\title{
Evidencialna branja prislova dizque v nekaterih različicah ameriške španščine in njegove ustreznice $v$ slovenščini
}

\begin{abstract}
Ključne besede: dizque, evidencialnost, epistemska naklonskost, ameriška španščina, slovenski naklonski členki
\end{abstract}

DOI: 10.4312/ars.11.2.85-103

\section{Uvod}

Prispevek obravnava izražanje evidencialnosti, ${ }^{1}$ torej kazanja na vir informacij v izjavi, v nekaterih ameriških različicah španščine ter izražene evidencialne vrednosti v izbranih literarnih besedilih primerja s slovenskimi ustreznicami.

Za začetek sodobnih evidencialnih študij veljajo antropološke raziskave Goddarda in Boasa z začetka 20. stoletja. ${ }^{2}$ Njihova avtorja med proučevanjem staroselskih jezikov opozorita na vrsto pripon, katerih vloga je kodifikacija vira informacij, zato jih v angleščino prevajata kot »it is said« ali »evently« (Izquierdo Alegría in dr., 2016, 10). Boas je tako eden prvih, ki v jezikoslovnih raziskavah uporabi izraz evidentiality.

Evidencialnost je konceptualno povezana s študijami o epistemski naklonskosti: če epistemska naklonskost razkriva, v kolikšni meri in na kakšen način se govorec zaveže resničnosti tega, kar trdi, se evidencialnost osredotoča na način pridobivanja informacij in vpisovanja virov informacij v izjavo, torej s "how one has knowledge of what one is saying « (Hardman, 1986, 115). V tej raziskavi nas bolj kot izražanje govorčeve sodbe o resničnosti posameznih propozicij zanima, na kakšen način je govorec prišel do informacije ter kako ta vir informacij vpisuje v svoje izjave. Osredotočamo se na evidencialna branja španskega prislova dizque ter analiziramo

$1 \quad \mathrm{~V}$ pričujoči študiji kot slovenski ustreznici angleških izvirnikov evidentiality in evidential uporabljamo izraza »evidencialnost « in »evidencialen«. V slovenskem prostoru je malo primerjalnih raziskav s slovenščino na tem področju, več se jih ukvarja $\mathrm{z}$ epistemsko naklonskostjo (npr. Pisanski Peterlin, 2015).

2 Na tem mestu velja omeniti, da že leta 1560 Domingo de Santo Tomás v delu Grammatica o arte de la lengua general de los indios de los reynos del Perú omenja določena obrazila v jeziku quechua, za katera ugotavlja, da so zgolj okras in da sama po sebi nič ne pomenijo. Šele mnogo kasneje, v 20. stoletju, je bilo ugotovljeno, da te pripone kažejo na način pridobitve informacije, o kateri je govora $\mathrm{v}$ sporočilu (Izquierdo Alegría in dr., 2016, 9). 
njegove ustreznice v slovenščini, kjer nas posebej zanimajo besedilne okoliščine, ko se $\mathrm{v}$ slovenščini s podobnimi evidencialnimi branji pojavijo naklonski členki.

\section{Epistemska naklonskost in evidencialnost}

Jezikovna modalnost oziroma naklonskost je osebno razmerje govorca do vsebine izjave in njene resničnosti ter hkrati »obvezni sestavni del upovedovanja in zato tudi konstitutivni (bistveni) del povedi, ker je izražena tudi sporočevalčeva doživljajskorazmerna plast « (Žele, 2008, 171). Znotraj naklonske sestavine jezikoslovje obravnava zelo raznolike pojavne oblike: glagolski naklon, modalne glagole, posamezne prislove in členke, intonacijo in podobno. Sistematična raba naklonskosti v jezikoslovju se začne $\mathrm{z}$ analizo diskurza in teorijo izjavljanja, ${ }^{3}$ znotraj katere je naklonskost »a form of participation by the speaker in the speech event " (Halliday, 1970, 335). Bally $(1942,3)$ jezikovno naklonskost utemelji kot morfološko spremembo, s katero se izraža subjektivnost v smislu izražanja govorčevih mnenj in sodb, ter vpelje osnovno razlikovanje med dictum in modus. Podobno Španska kraljeva akademija naklonskost opredeli kot izražanje govorčevega odnosa do vsebine sporočila in razlikuje med dvema tipoma naklonskosti: naklonskostjo izjavljanja, v okviru katere se realizirajo govorna dejanja, ter naklonskostjo izjave, ki se izraža prek določenih vrednosti glagolske fleksije in pomožnih glagolov (NGLE, 2009, 18).

$\mathrm{V}$ jezikovni opredelitvi naklonskosti je pogosto osnovno razlikovanje med epistemsko in deontično naklonskostjo, saj lahko pri večini jezikov hitro najdemo slovnične kategorije, ki izražajo te vsebine. Že Lyons (1977) na osnovi dveh osrednjih osi modalne logike, nujnosti (necessity) in možnosti (possibility), utemelji dva osnovna razreda naklonskosti, epistemično »which is concerned with matters of knowledge, belief" (Lyons, 1977, 793) in deontično "which is concerned with the necessity or possibility of acts performed by morally responsible agents« (Lyons, 1977, 823). Kasneje Palmer (1986, 2001) razlikuje med naklonskostjo dogodka (Event Modality), ki sestoji iz deontične in dinamične naklonskosti, in propozicijsko naklonskostjo (Propositional Modality), ki se deli na epistemsko in evidencialno naklonskost. Palmer torej epistemsko in evidencialno naklonskost razume kot povezani kategoriji:

Epistemic modality and evidential modality are concerned with the speaker's attitude to the truth-value or factual status of the proposition [...] With epistemic modality speakers express their judgements about the factual status of the proposition, whereas with evidential modality they indicate the evidence they have for its factual status (Palmer, 2001, 8).

3 Raziskovanje naklonskosti v jezikoslovje vstopi prek generativne semantike iz filozofije in modalne logike, kjer so osnovne in tradicionalne modalnosti tri: aletična, epistemična in deontična (Wright, 1951, 1-2). 
V sodobnih študijah o evidencialnosti in epistemski naklonskosti zasledimo t. i. širše in ožje razumevanje odnosa med obema kategorijama ter tri osnovne modalitete: prva izpostavlja njuno prepletanje, druga njuno izključevanje, tretja pa, da med njima obstaja določeno teoretsko presečišče (Dendale, Tasmowski, 2001, 341-342). S širšega zornega kota sta evidencialnost in epistemska naklonskost prepleteni kategoriji, ki sta vsebovani druga v drugi (npr. Palmer, 1986), ${ }^{4}$ saj naj bi bilo razkritje vira informacij vselej podrejeno epistemski zavezanosti govorca do povedanega. Nasprotno pa avtorji, ki izpostavljajo potrebo po ožjem razumevanju, razlikujejo med načinom pridobitve informacij in stopnjo zavezanosti govorca do gotovosti oziroma resničnosti izjave, saj prvo ne vključuje nujno drugega. Najpomembnejši zagovorniki tega pogleda, ki mu sledimo tudi v pričujoči raziskavi, so González Vázquez (2006), De Haan (2013), Aikhenvald (2004), Cornillie $(2009,2015)$ in drugi. Omeniti velja tudi tretji pogled, ki zagovarja stališče, da se evidencialnost in epistemska naklonskost delno prekrivata, predvsem kar zadeva inferencialno evidencialnost in epistemsko nujnost. Dejstvo je torej, da imata tako evidencialnost kot epistemska naklonskost opraviti z medosebno sestavino jezikovnega sporazumevanja, ki zadeva vlogo izrekanja v interakciji med govorcem in sogovorcem.

Informacije lahko pridobimo na različne načine: neposredno (direct evidence) ali posredno (indirect evidence), odvisno od tega, ali je vir informacij »of a primary or a secondary nature (Willett, 1988, 57). ${ }^{5} \mathrm{~V}$ prvem primeru govorec informacijo pridobi neposredno prek čutnih zaznav, je "priča« dejanju, ki ga opisuje, medtem ko gre $\mathrm{v}$ drugem primeru bodisi za informacijo iz druge roke (reported evidence) bodisi je rezultat govorčevega sklepanja (inferring evidence), to pa spet lahko temelji na oprijemljivih dokazih ali pa je miselni konstrukt (ibid.). V pričujoči študiji nas zanima predvsem to, kako se v izjavo vpisuje informacija, do katere govorec ni imel neposrednega dostopa, ter možnost, da lahko $\mathrm{z}$ istim jezikovnim sredstvom hkrati izražamo informacijo, ki jo je govorec slišal, in tisto, do katere je prišel s sklepanjem. V tovrstnih primerih se ustrezna evidencialna vrednost razkrije v konkretni sporočanjski situaciji.

Dejstvo je, da je prisotnost kazanja na vir informacij v izjavi v nekaterih, predvsem staroselskih jezikih obvezna, na primer v jeziku quechua (Aikhenvald, 2004, 42), v večini drugih, kot sta slovenščina in španščina, pa ne. Zato je razumljivo, da prihaja v sodobnih študijah tudi do razhajanj pri opredelitvah evidencialov (evidentials) oziroma evidencialnih elementov. Ponovno lahko izluščimo dva osnovna vidika: po mnenju nekaterih naj bi bili evidenciali vselej slovnično pogojeni (npr. Anderson, 1986), kar pomeni, da je njihova prisotnost obvezna, če želimo, da je stavek smiseln

4 Palmer pravi: »Epistemic and evidential systems are, in practise, not always wholly distinct « (Palmer, 1986, 24); podobno tudi Willet (1988), Chafe (1986) in NGLE (2009). 
in slovnično pravilen. Anderson zato opredeli štiri kriterije, ki jim mora zadostiti določen jezikovni element, da bi ga lahko obravnavali kot evidencialno kategorijo: jasno mora kazati na način pridobitve informacije, ne sme biti del glavne predikacije stavka, na vir informacije mora kazati s svojim primarnim pomenom in, ne nazadnje, morfološko gledano je lahko zgolj fleksija, klitika ali podoben skladenjski element, ne sme pa izhajati iz sestavljenih ali izpeljanih oblik (Anderson, 1986, 275). Ker indoevropski jeziki s takimi elementi načeloma ne razpolagajo, saj samo četrtina vseh svetovnih jezikov razpolaga $\mathrm{z}$ evidenciali kot posebnimi slovničnimi kategorijami (Aikhenvald, 2004, xii), je koncept evidencialov pogosto razumljen širše, s semantično osrediščenega zornega kota, in vključuje vse tiste jezikoslovne kategorije, ki v določenih kontekstih lahko ali morajo kazati na vir informacij s pomočjo t. i. evidencialnih strategij (Aikhenvald, 2004, 3). V pričujoči študiji izhajamo iz hipoteze, da so tako španskoameriški dizque kot nekateri slovenski naklonski členki (menda, baje) take jezikoslovne kategorije, zato jih (lahko) prištevamo med evidenciale oziroma t. i. evidencialne označevalce. ${ }^{6}$

\section{Dizque $v$ ameriških različicah španščine: od evidencialnega označevalca do epistemske naklonskosti}

Prislov dizque se $\mathrm{z}$ evidencialno in epistemsko naklonsko vlogo pojavlja v domala vseh različicah ameriške španščine, medtem ko v evropski španščini velja za arhaizem in se namesto njega uporablja diskurzivni označevalec al parecer. ${ }^{7}$ Že Kany (1944) opozori, da je mogoče obliko dizque zaslediti na skoraj vseh špansko govorečih področjih Amerike, v 20. stoletju pa je njena raba celo strmo narasla, kot dokazuje študija na podlagi analize korpusnih zbirk CORDE in CREA (Magaña, 2005). Zato so vse pogostejše raziskave o rabi tega prislova, še posebej v mehiški (npr. Olbertz, 2007) in kolumbijski španščini (npr. Travis, 2006). Po mnenju nekaterih naj bi šlo pri dizque za vpliv substrata (Alcázar, 2014), v tem primeru staroselskih jezikov Latinske Amerike, v katerih so evidencialni elementi obvezni. Tako se zdi logično sklepanje, da so jezikovni stiki med španskim jezikom in, na primer, jezikom quechua ${ }^{8}$ pospešili razvoj te slovnične kategorije tudi v ekvadorski in bolivijski španščini, še posebej na dvojezičnih področjih (Olbertz, 2005).

6 Angleško sintagmo evidential markers slovenimo »evidencialni označevalci« po analogiji s sintagmo »diskurzni označevalec« (po: Verdonik, 2007).

7 Dejstvo, ki je razvidno že pri površnem pogledu v katerikoli enojezični slovar, kot bomo videli kasneje.

8 Nekatere študije (de Granda, 2003) so celo pokazale, da se dizque pojavlja kot izposojenka v določenih različicah jezika quechua za krepitev evidencialnega pomena (Alcázar, 2014, 20). 
Omeniti velja še dejstvo, da v sodobnih enojezičnih slovarjih evropske španščine poleg prislova dizque ne stoji kvalifikator »zastarelo«, brez izjeme pa najdemo oznako, da gre za termin, ki se uporablja v ameriških različicah španščine. ${ }^{9}$ To potrjuje tudi korpus CORPES XXI (Korpus španščine 21. stoletja), saj je od 689 pojavitev v 343 dokumentih zgolj 9 pojavitev najdenih $\mathrm{v}$ besedilih $\mathrm{v}$ evropski španščini, ${ }^{10}$ najpogostejši pa je $\mathrm{v}$ mehiški, kolumbijski in čilski različici. $\mathrm{V}$ primeru mehiške španščine (ki zaznamuje večino analiziranega korpusa $\mathrm{v}$ tej raziskavi) velja omeniti nekatere diskrepance $\mathrm{v}$ sodobnih enojezičnih slovarjih: v Diccionario de mejicanismos avtorja F. J. Santamaría (1978) se geslo dizque sploh ne pojavi, medtem ko je v Diccionario del español usado en México (1996) opredeljen kot pogovorni element $z$ ironično konotacijo, ki se nanaša na informacijo dvomljive narave. Po drugi strani pa v Diccionario de mexicanismos (2010), ki je nastal pod okriljem mehiške akademije za jezik, beremo, da gre za pogovorni element, ki je sopomenka strukture al parecer. V sodobni mehiški španščini ima lahko dizque tudi konotacijo zastarelosti in podeželskosti (tako ugotavlja Eberenz, 2004, 140), čeprav v enojezičnih slovarjih tega podatka ni mogoče zaslediti.

\subsection{Oblikoslovno-skladenjska in pomenska raven}

Etimološki izvor prislova dizque je nesporen: ${ }^{11}$ diz je skrajšana oblika srednjeveške oblike dize in znano je, da je pojav t. i. splošne apokope, ki je značilna za kastiljščino 12. in 13. stoletja, prizadel tudi nekatere glagolske oblike: npr. velelnik (kar je razvidno v sodobnih oblikah haz, pon, sal, ven ...) in tretjo osebo sedanjika (diz, sal, pon, tien, vien, quier) (Eberenz, 2004, 141). Po 14. stoletju se ti nenaglašeni vokali »vrnejo«, oblika diz pa se uporablja še naprej in se počasi gramatikalizira, saj izgublja pomen tretje osebe glagola decir in postaja sestavni del prislova. Kot pokaže Kany $(1944,1969)$, je bila struktura diz que v stari evropski španščini pogosta in je pomenila "pravijo, da" (dice que) oziroma tudi neosebno "govori se, da" (se dice que). Od 15. stoletja dalje je razvidno, da se dizque uporablja brez reference na eksplicitnega ali implicitnega govorca (Eberenz, 2004, 151), po letu 1500 pa je začela njegova raba počasi upadati, vendar ne izgine, temveč pridobi pogovorno-provincialni, celo rustikalni značaj in se v pokrajinski literaturi obdrži vse do 19. stoletja (Kany, 1969). Dejstvo je, da je struktura od 15. stoletja dalje v procesu frazeološke sistematizacije in celo desemantizacije, kar

9 Poglejmo nekaj primerov: »Am. Al parecer, presuntamente« (DRAE, 23ª s.v.), »En zonas del español meridional, al parecer« (CLAVE, s.v.), »Origen: América. Según parece, por lo visto. (Diccionario de Salamanca, s.v.); »En el español de amplias zonas de América sigue vigente el uso de esta expresión [...]. Se usa normalmente como adverbio, con el sentido de 'al parecer' o 'supuestamente'" (Diccionario de dudas, s.v.).

10 http://web.frl.es/CORPES/org/publico/pages/consulta/entradaCompleja.view [4. 7. 2017].

11 V NGLE beremo: "La antigua forma monosilábica diz, que no se usó como imperativo, pervive hoy en el adverbio dizque ('al parecer, presuntamente'), más usado en ciertas áreas del español americano« $(2010,67)$. 
dokazuje hkratna raba z glagolom decir: "dizque dixo", »decían dizque" (Eberenz, 2007, 152). V sodobni ekvadorski španščini je na primer zveza z glagolom decir tako pogosta, da je »dizque dijo« postala običajna struktura za uvajanje poročanega govora (Olbertz, 2005, 5). Po drugi strani Demonte in Fernandez Soriano $(2013,7)$ trdita, da je dizque nekakšna vmesna etapa v procesu gramatikalizacije, ki se je začel s strukturo z glagolom rekanja »dicen que«, končal pa se bo z evidencialnim »que«. To argumentirata tudi z morfološko heterogenostjo, ki je še najizrazitejša $v$ mehiški španščini: izque, isque, i que/ y que, es que, quizque, quesque idr. (Demonte, Fernández Soriano, 2013, 6, tudi: Kany, 1944, 174).

Heterogena je tudi besednovrstna vloga dizque v sodobnih različicah ameriške španščine: v Diccionario de Americanismos (2010), ki je nastal pod okriljem združenih akademij za španski jezik, je navedeno, da gre sicer v večini primerov za prislov, lahko pa je tudi pridevnik (Bolivija, Mehika, Kostarika, Peru) s pomenom presunto ali pretendido (tako imenovan), ${ }^{12} \mathrm{v}$ bolivijski španščini pa je lahko celo samostalnik moškega spola s pomenom habladurías, murmuraciones (govorice) (Diccionario de americanismos, s.v. »dizque«). Oblikoslovno-skladenjski značaj dizque je v ameriških različicah španščine specifičen: poleg večje ali manjše gramatikalizacije same oblike in možnega pisanja skupaj ali narazen velja omeniti precejšnjo skladenjsko prilagodljivost, saj lahko modificira tako glavni kot odvisni stavek, samostalniško ali prislovno zvezo ter celo vrsto predikatov (Olbertz, 2007, 151). Dizque torej načeloma zaseda neobvezna skladenjska mesta, ${ }^{13}$ zato se zaradi kategorizacijskega in semantičnega oddaljevanja od glagola decir (reči) mestoma celo zdi, da se obnaša bolj kot členek, ${ }^{14}$ saj lahko igra različne semantične in pragmatične vloge (npr. citatno, poročano, epistemsko ...). Nekatere študije (npr. Travis, 2006) celo trdijo, da bi bilo treba razločevati med dizque kot členkom in dizque kot prislovom. V tej študiji sicer sledimo opredelitvi Olbertzove, ki poudarja njegovo primarno prislovno vlogo: »an adverbial expression of reportative evidentialiy, i. e. it expresses an objective distance between the speaker and the contents she/he communicates« (Olbertz, 2007, 151).

\subsection{Besedilnotvorna in pragmatskosporočilna raven}

$\mathrm{V}$ ameriških različicah španščine ima prislov dizque $\mathrm{v}$ besedilih pogosto vlogo diskurzivnega označevalca; kot tak se najprej utrdi $\mathrm{v}$ uradnih, nato $\mathrm{v}$ literarnih in

12 Ko se govorec želi oddaljiti od propozicijske vsebine: sus dizque amigos so njegovi »tako imenovani« prijatelji, »so-called « friends (Obertz, 2007, 152).

13 Izjema je ekvadorska španščina, kjer mora obvezno stati tik pred glagolom (Alcázar, 2017; Olbertz, $2005,90)$.

14 Opozoriti velja na razliko med slovenskim členkom kot besedno vrsto ter španskim členkom: v španskem sistemu je členek oziroma partícula katerakoli nepregibna besedna vrsta (oziralni zaimek, veznik ...), ki izraža slovnične pomene in relacije (DRAE, s.v.). 
pesniških besedilih, v zadnjih desetletjih pa je prešel v govorjeni diskurz (Eberenz, 2004, 151). Semantični razvoj gre tako iz striktno metadiskurzivne vloge do evidencialne in gotovostne vrednosti (že v 15. stoletju, kot ugotavlja Olbertz, 2005, 2007), ki v nekaterih sodobnih ameriških različicah španščine že prehaja v epistemsko naklonsko vrednost. Dizque je torej kategorija, za katero se zdi, da lahko hkrati kaže na vir informacij in slabi gotovostno naklonskost, vendar pa ne v enaki meri v vseh različicah ameriške španščine. V mehiški in kolumbijski španščini, kjer dizque deluje kot stavčni modifikator, sicer prevladuje evidencialna raba (pravijo, da), vendar pa je mogoče $\mathrm{v}$ mehiški španščini zaslediti tudi primere, ko dizque sicer signalizira objektivno razdaljo govorca do informacije iz druge roke, vendar hkrati implicira njegov dvom v verodostojnost informacije (Olbertz, 2007, 151). Nekatere druge študije (Kany, 1944; Laprade, 1976; Travis, 2006) prav tako poudarjajo širše referenčno polje tega prislova $\mathrm{v}$ ameriški španščini, saj naj bi kot uvajalni element v poročani govor označeval podtone tako dvoma kot tudi negativnega odnosa govorca do veljavnosti informacije (Travis, 2006, 1270).

\section{Nekatere slovenske ustreznice evidencialnega označevalca dizque}

Glede na oblikoslovno-skladenjske in semantično-pragmatske značilnosti prislova dizque smo postavili hipotezo, da so mu pri signaliziranju evidencialnih vrednosti $\mathrm{v}$ slovenščini najbližji nekateri naklonski členki, predvsem menda in baje, pa tudi češ da, zato v tem poglavju najprej pretresemo osnovne vzporednice med temi kategorijami, zatem pa analiziramo nekaj primerov rabe v izbranem korpusu leposlovnih besedil. Predstavljamo zgolj nekatere izsledke, saj gre za širše zasnovano raziskavo, ki bo vključevala tudi primere govorjenega diskurza.

Če najprej pregledamo stanje $\mathrm{v}$ obstoječih dvojezičnih špansko-slovenskih slovarjih, ${ }^{15}$ hitro ugotovimo, da se dizque kot samostojno geslo ne pojavi v nobenem od njih, kar je razumljivo, saj je bila pri vseh osnova za nabor korpusa evropska španščina. Omeniti pa velja, da se dizque (skupaj z oznako Am) pojavi v Ponsovem slovarju (2010) kot španska ustreznica slovenskega členka menda, skupaj s sopomenko al parecer (PONS, s.v. »menda«), ki je evidencialni označevalec v evropski španščini ${ }^{16}$ in sintagma, ki se, po drugi strani, najpogosteje navaja kot španska ustreznica členka baje v slovensko-španskih slovarjih (Grad, 1979, Moderni slovar, 2005, Splošni slovar, 2007),

15 Oba Gradova slovarja (1979), Moderni (2002) ter Splošni (2007) slovar Cankarjeve Založbe (Markič in dr.) in PONS (2010).

16 »Indica que el hablante no es testigo directo de la información transmitida y que la ha adquirido por las fuentes externas del mismo« (Diccionario de partículas discursivas, http://www.dpde.es/) [4. 7. 2017]. 
in sicer poleg dicen, a lo que parece, se murmura, se rumorea. Povezava med dizque in baje ter tudi menda je hkrati razvidna v etimološki zasnovi: pri vseh je bila prvotna oblika tretja oseba glagola in podredni veznik: $\mathrm{v}$ španščini dice que, $\mathrm{v}$ slovenščini baja da, meni da (Snoj, 2003, 28, 392). Zanimivo je, da se je sklop menda prvotno uporabljal kot uvodni stavek v odvisni govor (Snoj, 2003, 392); v govorjenem diskurzu je taka raba pogosta še danes, podobno kot v ekvadorski španščini že omenjena zveza dizque dijo. Če pri dizque še vedno prepoznamo prvotni glagol rekanja, se pri menda in baje zdi, da sta povsem gramatikalizirani enoti, saj sta tretji osebi odgovarjajočih glagolov (bajati in meniti) ter podredni veznik (da) spojeni v novo besedno vrsto, katere pomen naj ne bi bil več odvisen od seštevka posameznih besed. Kljub temu evidencialna raba teh dveh členkov kaže, da etimološki izvor, vsaj pri baje, še vedno delno vpliva na pomen.

\section{1 Slovenski naklonski členki kot evidencialni označevalci}

Tradicionalna slovenska slovnica členke najprej obravnava kot podvrsto prislovov, šele v sedemdesetih letih prejšnjega stoletja jih jezikoslovec Jože Toporišič opredeli kot samostojno besedno vrsto in jih v skladu s semantičnimi kriteriji razdeliv trinajst skupin, vendar tudi tedaj eksplicitno zapiše, da se nekateri po vlogi približujejo prislovom, drugi veznikom (Toporišič, 1976, 384). V sodobnem slovenskem jezikoslovju načeloma velja, da je členek nepregibna besedna vrsta, ki nima vprašalnice, zaradi njegovih specifičnih skladenjskih vlog pa še vedno prihaja do razhajanj pri natančnejših opredelitvah v jezikoslovnih priročnikih in slovarjih (SSKJ $1,{ }^{17}$ Slovenski pravopis ${ }^{18}$ itd.), na kar opozarja tudi Smolej (2015). V zadnji izdaji slovenske slovnice beremo, da s členki "vzpostavljamo zveze s sobesedilom, izražamo pomenske odtenke posameznih besed, delov stavka, celih stavkov in povedi ali pa tvorimo skladenjske naklone« (Toporišič, 2000, 445), v slovarju slovenskih členkov (Žele, 2014) pa je členek opredeljen kot nesamostojna skladenjskofunkcijska besedna vrsta, oziroma kot »strnjeni ubesedeni govorni dogodek, [...] ki opozarja na spremenjene okoliščine besedila« (Žele, 2014, 9). Žele (2014) glede na sporočanjsko-pragmatični vidik razlikuje dve krovni skupini členkov: povezovalne ali besedilne členke, »ki izhajajo iz pragmatičnih okoliščin in jih vključujejo v besedilo« $(2014,10)$, ter naklonske ali medosebne členke, »ki izhajajo iz sporočanjskih razmerij in vplivanj med udeleženci diskurza« (ibid.). Po drugi strani Smolej (2004a) členke razdeli glede na njihovo obveznost in neobveznost v povedi in besedilu ter razlikuje med skupino pritrdilnih in nikalnih členkov, skupino tvorcev stalnih sporočanjskih oblik povedi, skupino modalnih členkov, skupino členkov čustvovanja, skupino poudarjalnih členkov in skupino navezovalnih členkov oziroma

17 SSKJ 1 je izdaja iz leta 1997 (dostopna tudi na spletu); v njem sta menda in baje opredeljena kot prislova.

V Slovenskem pravopisu (2001) sta menda in baje opredeljena kot členka. 
besedilnih povezovalcev (Smolej, 2004a, 144). Baje in menda sta torej po Smolej (2004a, 147) del skupine enostopenjsko obveznih ${ }^{19}$ modalnih členkov, ki se funkcijsko udejanjajo bodisi kot vnašalci subjektivnega stališča govorca bodisi kot sredstva krepitve in slabljenja gotovostne naklonskosti. Konkretna modifikacija menda in baje je razvidna kot pomenska dopolnitev vsebine povedi (Smolej, 2004a, 143). ${ }^{20}$

V pričujoči študiji želimo pokazati, da sta lahko naklonska členka baje in menda $\mathrm{z}$ besedilnotvornega in sporočilnega vidika tudi evidencialna elementa, ki kažeta na citatni vir informacij oziroma poročano evidencialnost (po: Willet, 1988); še posebej se zdi to očitno pri baje (in njegovi sopomenki bojda). V Slovarju slovenskih členkov lahko sicer v sestavku za baje razberemo, da ta naklonsko vrednotenjski členek izraža različno stopnjo verjetnosti sporočanja (Žele, 2014, 18). Na istem mestu je navedeno, da sta menda in baje istosporočilna predvsem takrat, ko kažeta na zunanji vir informacij (Baje, da so uspeli|Menda, tako pravijo) (ibid.), kar dokazuje, da sta oba lahko v vlogi evidencialnega označevalca. Po drugi strani v slovarskem sestavku za menda ni nobenega eksplicitnega zapisa, da lahko členek kaže tudi na vir informacij, pač pa je poudarek na epistemsko naklonski vlogi: kot naklonsko vrednotenjski členek izraža domnevo, torej gotovostno naklonskost slabi, npr. »Menda pride«, kot naklonsko čustvenostni pa jo krepi, saj izraža soglasje, pritrjevanje brez pridržka, »Menda ja!« (Žele, 2014, 43). Členek menda lahko poved modificira bolj kompleksno, zato ne preseneča, da je pogostejši kot baje, ki na splošno velja za manj rabljenega predvsem v pisnih besedilih. To dokazuje že površen pogled v referenčni korpus Gigafida: 135.929 konkordanc členka menda proti 14.158 konkordancam členka baje. ${ }^{21}$ Podobno v korpusu Kres: 9.237 za menda proti 1275 konkordancam za baje. Obratno pa je v korpusu govorjene slovenščine (Gos): baje ima 123 konkordanc, medtem ko jih ima menda 79. Zdi se torej, da je členek baje pogostejši v govorjenem jeziku.

\subsection{Analiza primerov}

$\mathrm{V}$ nadaljevanju predstavimo slovenske ustreznice prislova dizque $\mathrm{v}$ izbranih leposlovnih besedilih ter analiziramo njegove evidencialne in epistemsko-naklonske vrednosti. Korpus sestoji iz sedmih leposlovnih del štirih latinskoameriških avtorjev in njihovih prevodov v slovenščino: ${ }^{22}$ dveh del čilskega pisatelja Roberta Bolaña (2666

19 Enostopenjska obveznost po Smolej pomeni, da njihova odstranitev iz povedi povzroči prekinitev besedilnega toka oziroma besedilnega smisla, ne pa tudi sporočanjske oblike povedi (Smolej, 2004a, 142).

20 Briz (2016) podobno trdi za španske evidencialne označevalce (na primer al parecer, ki se v dvojezičnem slovaropisju pojavi tudi kot ustreznica členku menda).

21 Datum dostopa v vse navedene spletne korpuse v tem odstavku: 26. 7. 2017.

22 Posebna pozornost je veljala tudi izboru različnih prevajalcev, saj lahko prevajalčev osebni slog predstavlja manj ustrezne okoliščine za legitimne zaključke raziskave. 
in Detectives salvajes), dveh del perujskega pisatelja Maria Vargasa Llose (Quién mató a Palomino Molero in Héroe secreto), dveh del mehiškega pisatelja Carlosa Fuentesa (Cambios de piel in La muerte de Artemio Cruz) ter najpomembnejšega dela mehiškega pisatelja Juana Rulfa, Pedro Páramo. Pri slednjem smo v analizi upoštevali oba obstoječa prevoda (1970 in 2017). Dizque ima v izbranem korpusu 24 pojavitev, od tega je najpogostejši (14 pojavitev) v obeh delih Bolaña, sledi delo Juana Rulfa (5 pojavitev), $\mathrm{v}$ ostalih pa se pojavi enkrat oziroma dvakrat. V štirih pojavitvah je del samostalniške besedne zveze $\mathrm{z}$ vlogo vzpostavljanja govorčeve oddaljitve od propozicijske vsebine, vselej pri delih mehiških ${ }^{23}$ avtorjev. Kot evidencialni označevalec s poročano vrednostjo se pojavi v šestnajstih $(66,66 \%)$ primerih, v petih pojavitvah $(20,83 \%)$ pa slabi gotovostno naklonskost. $\mathrm{V}$ treh primerih $\mathrm{v}$ slovenskem prevodu ni ustreznice, $\mathrm{v}$ enem pa je dizque prenesen kot del lastnega imena: Dizque Chippendale, dice mi mamá (Fuentes, 1991, 77). $\rightarrow$ Dizque Chippendale, pravi moja mama (Fuentes, 2003, 151).

\subsection{Slovenske ustreznice dizque $z$ evidencialno in epistemsko-naklonsko vrednostjo}

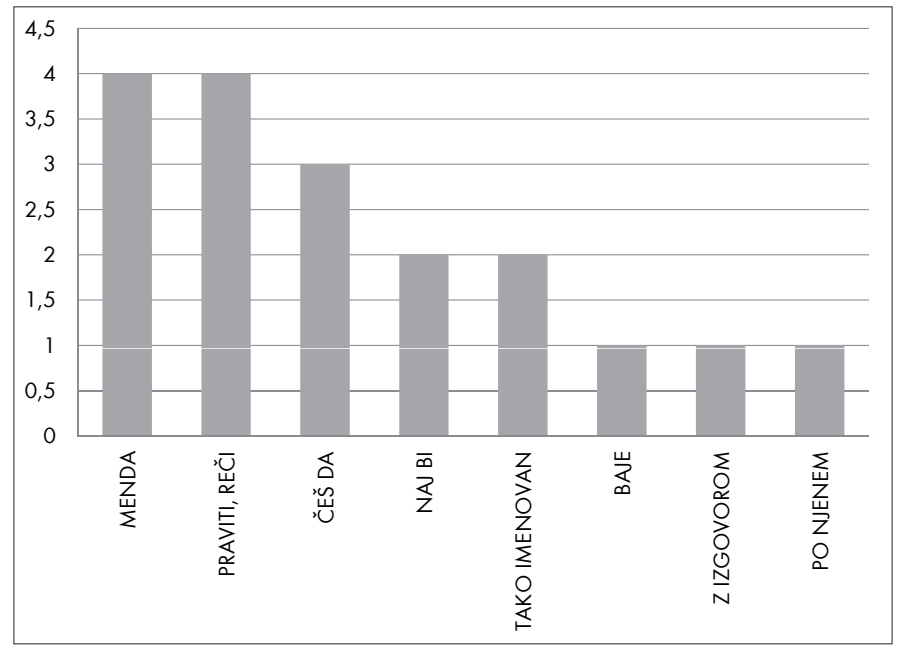

Tabela 1: Slovenske ustreznice dizque z evidencialno in epistemsko-naklonsko vrednostjo $\mathrm{v}$ analiziranem korpusu.

$\mathrm{V}$ primerih, ko ima dizque evidencialno vrednost, so najpogostejše ustreznice te: menda, praviti/reči (kot pravijo, kjer pravijo, kako že pravi, ki je rekla), češ da, naj bi, baje, z izgovorom, po njenem. Navajamo in komentiramo po en primer za vsako ustreznico.

23 Kot pridevnik se lahko pojavlja v bolivijski, mehiški, kostariški, kolumbijski in perujski španščini (Diccionario de americanismos, s.v. »dizque«). 


\subsection{1 dizque $\rightarrow$ menda}

Menda kaže na zunanji vir informacije:

1) En el interrogatorio al que fueron sometidos Carlos Camilo Alonso perdió todos los dientes y sufrió rotura del tabique nasal, dizque en un intento de suicidio (Bolaño, 2009, 461).

1a) V času zasliševanj, ki sta jih prestajala, je Carlos Camilo Alonso izgubil vse zobe in utrpel zlom nosnega pretina, menda je šlo za poskus samomora (Bolaño, 2013, 186).

\subsection{2 dizque $\rightarrow$ glagol praviti, reči}

Evidencialni značaj dizque je očiten pri ustreznicah $\mathrm{z}$ glagolom praviti, reči. Trdimo, da bi lahko enako vrednost izrazili tudi s členkoma menda in baje (... hčere, ki jo je baje/menda zlorabil):

2) Y como saben lo que le gusta a la gente, inventaron esa inmundicia de que se había cargado a Molero por celos de una hija a la que dizque abusaba (Vargas Llosa, 1986, 120).

2a) A ker jim je znano, kaj ljudje radi slišijo, so si izmislili to packarijo, da se je Palomina Molera odkrižal iz ljubosumnosti do hčere, ki jo je, kot pravijo, zlorabil (Vargas Llosa, 1988, 134).

\subsection{3 dizque $\rightarrow$ češ da}

Po pogostosti je na tretjem mestu povezovalni pojasnjevalni členek češ ${ }^{24} \mathrm{da}$, ki uvaja pojasnilo v obliki prevzete izjave (Žele, 2010, 22):

3) Y, como sabrás, a Miguelito lo metió al Ejército, dizque para enderezarlo, porque se le andaba torciendo (Vargas Llosa, 2013a, 110).

3a) Kot najbrž veš, je Miguelita vrgel v vojsko, češ da ga bo utrdil, ker se je začel nespodobno obnašati (Vargas Llosa, 2013b, 117).

\subsection{4 dizque $\rightarrow$ naj bi}

4) ... que se encargaría de localizar, con apoyo de la policía municipal, el Peregrino o el Arquero o el Lincoln en donde dizque las secuestraron (Bolaño, 2009, 449).

4a) ... kje je peregrino ali arquero ali lincoln, s katerim naj bi bili deklici ugrabljeni (Bolaño, 2013, 177).

Členek naj s pogojnim naklonom v slovenščini izraža domnevo, kar ustreza izvirniku 4), kjer ima dizque vrednost slabljenja gotovostne naklonskosti in manj poudarjeno evidencialno vrednost.

24 »Izvorno glagolska oblika, nastala iz hčèš, 2. osebe sed. glagola htéti, različice od hotéti« (Snoj, 2003, 84). 


\subsection{5 dizque $\rightarrow$ baje}

5) Una vez pensé que era por culpa de Ernesto San Epifanio, Arturo y él fueron amigos cuando ninguno de los dos tenía veinte años, antes de que Arturo se marchara a Chile dizque a hacer la Revolución... (Bolaño, 1997, 175).

5a) Včasih si mislim, da zaradi Ernesta San Epifania, Arturo in on sta bila prijatelja, ko še nobenemu od njiju ni bilo dvajset let, preden je Arturo odšel iz Čila, baje zato, da bi se šel Revolucijo ... (Bolaño, 2012, 216).

Slovenska ustreznica baje ima $\mathrm{v}$ tem primeru nedvomno poročano vrednost (pravijo, da). V analiziranih primerih se kot ustreznica dizque pojavi samo enkrat.

Dizque ima specifično vlogo, kadar nastopa v samostalniški besedni zvezi. Govorec z njegovo pomočjo izraža določen zadržek in slabi gotovostno naklonskost. $\mathrm{V}$ izbranem korpusu se od 24 pojavitev taka vrednost pojavi $\mathrm{v}$ štirih primerih. Dvakrat ni prevedena, $\mathrm{v}$ dveh primerih pa je prevedena $\mathrm{z}$ besedno zvezo »tako imenovan «:

6) Infórmele a la oficina central que si este dizque movimiento de depuración sindical triunfa, ya podemos cortarnos la coleta... (Fuentes, 1977b, 51).

6a) Povejte v centralnem biroju, če bo tako imenovana čistka uspela, lahko stisnemo rep med noge ... (Fuentes, 1977b, 63).

\subsection{Primeriava slovenskih ustreznic dizque $v$ dveh prevodih dela Pedro Páramo}

Posebno pozornost smo v raziskavi posvetili analizi dveh obstoječih prevodov ${ }^{25}$ enega ključnih latinskoameriških in svetovnih romanov, Pedro Páramo španskega pisatelja Juana Rulfa. Najočitnejša razlika je, da se v sodobnejšem prevodu dizque v treh od petih primerov sloveni s členki. V nadaljevanju navajamo in komentiramo vseh pet izvirnih primerov in obe prevodni različici.

7) Fue lo primero que le dijo el Aldrete, después que se habían estado emborrachando juntos, dizque para celebrar el acta $(1992,32)$.

7a) To je bilo prvo, kar mu je rekel Aldrete, potem ko sta se napila z izgovorom, da proslavljata dejanje $(1970,37)$.

7b) Bilo je prvo, kar mu je bil rekel Aldrete, potem ko sta se ga skupaj napila, češ da je treba tožbo zapiti $(2017,47)$.

Zdi se, da se evidencialna poročana vrednost v primeru $7 \mathrm{v}$ sodobnejši različici učinkoviteje prenese s kompaktnejšo obliko, in sicer $\mathrm{z}$ domnevnostnim členkom češ da, ki v slovenščini uvaja pojasnilo v obliki prevzete izjave. 
8) Ahora ya sé de qué se trata y me da risa. Dizque «usufruto». Vergüenza debía darle a su patrón ser tan ignorante (1992, 32).

8a) Zdaj že vem, pri čem sem, in pošteno mi gre na smeh. Kako že pravi: "prisvajanje tujega imetja«. Vašega gospodarja bi moralo biti sram spričo tolikšnega neznanja $(1970,38)$.

8b) Zdaj ko že vem, koliko ura bije, mi gre na smeh. "Protipostavni užitek « - pa ja. Sram naj ga bo, vašega gospodarja, da je tako neuk $(2017,48)$.

V primeru 8) se slabi gotovostna naklonskost, izražen je govorčev negativni odnos do veljavnosti informacije, zato se zdi ustreznejša prevodna rešitev 8b): pa ja učinkoviteje prenese ironični podton, ki sporoča nasprotje od soglasja.

9) Después se había comportado como un collón, dando de gritos. «Dizque la fuerza que yo tenía atrás» $(1992,32)$.

9a) Pozneje se je obnašal kot strahopetec, kričal je: »Močno podporo imam, mar $\underline{\text { ne? }}$ « $(1970,38)$.

9b) Potem se je vedel kot usran zajec in se drl: "Polnomočje oblasti, ki me je vpregla, kaj? « $(2017,48)$.

Tudi v primeru 9) gre za slabitev gotovostne naklonskosti in izražanje negativnega odnosa govorca do veljavnosti informacije, kar se kot implikatura prenese v obeh primerih, ne glede na pričakovanje potrditve s strani govorca (mar ne? kaj?).

10) Estaba muy enferma. Dicen que ya no conocía a la gente, y dizque hablaba sola (1992, 108).

10a) Bila je hudo bolna. Pravijo, da ni nikogar več poznala in da je govorila samo še sama s seboj $(1970,115)$.

10b)Zelo bolna je bila. Pravijo, da nikogar več ni poznala in da je menda govorila sama s sabo $(2017,110)$.

V primeru 10a) dizque ostane brez ustreznice, verjetno tudi zato, ker se zdi, da je glagol rekanja na začetku stavka dovolj. V primeru 10b) se zdi, da se ustrezneje obdrži dvojnost izvirnih struktur dicen que in dizque s slovenskima in da ter menda, ki je tu v vlogi evidencialnega označevalca.

11) La que le dio aquel hijito que se les murió apenas nacido, dizque porque ella estaba incapacitada... (1992, 119).

11a) Cuca, ki mu je dala sinčka, ki je umrl že ob rojstvu, bržkone zato, ker je bila bolehna ... $(1970,126)$.

11b) Cuca, ki mu je dala tistega sinčka, ki jima je umrl ob rojstvu, menda zaradi njene onemoglosti ... $(2017,118)$.

Členek bržkone izraža precejšnjo verjetnost (Žele, 2014, 21), torej epistemsko naklonskost; njegova izbira v 11a) je verjetno pogojena tudi zaradi reference na 
preteklo dejanje, medtem ko členek menda v 11b) po našem mnenju obdrži dvojno branje izvirnika dizque, ki je lahko v tem primeru evidencialno (pravijo, da zato, ker je bila onemogla) in epistemsko-naklonsko (verjetno zato, ker je bila onemogla).

\section{Zaključek}

V študiji smo predstavili evidencialna branja prislova dizque, ki ga zaznamuje tako besednovrstna heterogenost, saj je lahko prislov, pridevnik ali, redkeje, samostalnik, kot tudi skladenjskopomenska in pragmatskosporočilna večplastnost. Pojavlja se $\mathrm{v}$ domala vseh različicah ameriške španščine ter je ravno zaradi te heterogenosti in naraščajoče rabe $\mathrm{v}$ različnih, tudi dvojezičnih jezikovnih okoljih podvržen raznim procesom gramatikalizacije in leksikalizacije. Predstavili smo nekatere strukturne podobnosti in pragmatska ujemanja s slovenskimi naklonskimi členki ter pokazali, da na besedilni ravni pogosto deluje kot evidencialni označevalec.

Analiza izbranega korpusa je potrdila, da je poleg zveze z glagolom rekanja, ki se povezuje $\mathrm{z}$ izvirno strukturo dice que, najpogostejša slovenska ustreznica španskoameriškemu dizque modalni členek menda, predvsem kadar gre za signaliziranje poročanih evidencialnih pomenov, torej vpisovanja sekundarnega vira informacij v izjavo. Hkrati je pokazala, da je možna evidencialna ustreznica tudi povezovalno pojasnjevalni členek češ da, ki prav tako izraža, da je bila informacija pridobljena iz drugega vira. Pri epistemsko-naklonski vlogi velja izpostaviti členek bržkone, ki v slovenščini izraža precejšnjo verjetnost. Presenetljivo pa je, da se modalni členek baje kot ustreznica evidencialnemu dizque pojavi samo enkrat, posebej zato, ker se zdi, da se po etimološkem izvoru ter skladenjskih in pomenskopragmatskih značilnostih najbolj približa izvirniku. Pri vseh primerih evidencialnih branj se je pokazalo, da so poleg skladenjske in pomenske ravni proučevanja bistvene tudi besedilnotvorne zmožnosti in pragmatske vrednosti, ki omogočajo bodisi evidencialne bodisi epistemske vrednosti v konkretnih primerih rabe. Analiza slovenskih prevodnih ustreznic je pokazala, da lahko tako dizque kot slovenski členki baje, menda in češ da izražajo poročani govor, citiranje, sklepanje in predvidevanje, vendar pa je njihova primarna pomenska vrednost še vedno vpisovanje vira informacij v izjavo.

\section{Bibliografija}

\section{Viri}

Bolaño, R., 2666, New York 2009.

Bolaño, R., 2666, 2. knjiga, (prev. Irena Levičar), Ljubljana 2013. 
Bolaño, R., Detectives salvajes, Barcelona 1997.

Bolaño, R., Divji detektivi, (prev. Veronika Rot), Ljubljana 2012.

Fuentes, C., Cambio de piel, Barcelona 1991.

Fuentes, C., La muerte de Artemio Cruz 1977a.

Fuentes, C., Levitev, (prev. Miro Bajt), Ljubljana 2003.

Fuentes, C., Smrt Artemia Cruza, prev. Alenka Bole Vrabec, Murska Sobota 1977b.

Páramo, P., Juan Rulfo, Madrid, 1992.

Páramo, P., Juan Rulfo, (prev. Alenka Bole Vrabec), Ljubljana 1970.

Páramo, P., Juan Rulfo, (prev. Vesna Velkavrh Bukilica), Ljubljana 2017.

Vargas Llosa, M., ¿Quién mató a Palomino Molero?, Barcelona 1986.

Vargas Llosa, M., El Heróe discreto, Madrid 2013a.

Vargas Llosa, M., Kdo je ubil Palomina Molera, (prev. Nina Kovič), Murska Sobota 1988.

Vargas Llosa, M., Prikriti junak, (prev. Katja Mrak), Ljubljana 2013 b.

\section{Slovarii}

Asociación de Academias de la Lengua Española, Diccionario de americanismos, 2010, http://www.asale.org/recursos/diccionarios/damer [1. 9. 2017].

Grad, A., Slovensko- španski slovar. Diccionario esloveno-español, Ljubljana 1979.

ISJ ZRC SAZU, Slovar slovenskega knjižnega jezika (SSKJ 1), http://www.fran.si [1. 9. 2017].

ISJ ZRC SAZU, Slovenski pravopis, http://bos.zrc-sazu.si/sp2001.html [1. 9. 2017].

Markič, J. in dr., Špansko-slovenski in slovensko-španski moderni slovar. Diccionario moderno español-esloveno y esloveno-español, Ljubljana 2005.

Markič, J. in dr., Špansko-slovenski in slovensko-španski splošni slovar. Diccionario general español-esloveno y esloveno-español, Ljubljana 2007.

PONS, Šolski slovar. Španščina. Diccionario escolar. Español, Ljubljana 2010.

Real Academia Española, Diccionario de la lengua española. Vigésima tercera edición, http://www.rae.es/recursos/diccionarios/drae [1. 9. 2017].

Snoj, M., Slovenski etimološki slovar, Ljubljana 2003.

Žele, A., Slovar slovenskih členkov, Ljubljana 2014. 


\section{Spletni korpusi}

Korpus slovenskega jezika Gigafida, http://www.gigafida.net/ [12. 9. 2017].

Korpus govorjene slovenščine GOS, http://www.korpus-gos.net/ [12. 9. 2017].

Korpus Kres, http://www.korpus-kres.net/ [12.9. 2017].

Real Academia Española, CORDE, en línea, Corpus diacrónico del español, http:// www.rae.es [15. 9. 2017].

Real Academia Española, CREA, Corpus de referencia del español actual http://www. rae.es [15. 9. 2017].

Real Academia Española, CORPES XXI, Corpus del Español del Siglo XXI, http://web. frl.es/CORPES [15. 9. 2017].

\section{Literatura}

Aikhenvald, A., Evidentiality, Oxford 2004.

Aikhenvald, A., Information Source and Evidentiality: What can we conclude?, Italian Journal of Linguistics 19, 2007, str. 209-227.

Alcázar, A., Dizque and other emergent evidential forms. The Oxford Handbook of Evidentiality, (ur. Aikhenvald, A.), Oxford (v tisku), https://research.jcu.edu.au/ lcrc/.../evidentiality/draft-chapters.../file [20. 6. 2017].

Alcázar, A., On the grammaticalization of dizque, v: Perspectives in the study of Spanish Language Variation (ur. Enrique Arias, A., Gutiérrez, M. J., Landa, A., Ocampo, F.), Santiago de Compostela 2014, str. 17-40.

Cornillie, B., Evidentiality and epistemic modality: On the close relationship between two different categories, Functions of Language 16/1, 2009, str. 44-62.

Cornillie, B., Más allá de la epistemicidad. Las funciones discursivas de los adverbios epistémicos y evidenciales en el español conversacional, Spanish in Context 12/1, 2015, str. $120-139$.

De Haan, F., Semantic Distinctions of Evidentiality, v: The World Atlas of Language Structures Online (ur. Dryer, M. S., Haspelmath, M.), Leipzig 2013, http://wals. info/chapter/77 [28. 6. 2017].

Demonte, V., Fernández-Soriano, O., Evidentials dizque and que in Spanish: Grammaticalization, parameters and the (fine) structure of Comp. Linguística, Revista de Estudos linguísticos da Universidade do Porto 8, 2013, str. 211-234.

Dendale, P., Tasmowski, L., Introduction: Evidentiality and related notions, Journal of Pragmatics 33/3, 2001, str. 339-348.

Eberenz, R., Dizque: antecedentes medievales de un arcaísmo afortunado, Lexis XXVIII/1-2, 2004, str. 139-156. 
González Vázquez, M., Las fuentes de la información: Tipología, semántica y pragmática de la evidencialidad, Vigo 2006.

Hardman, M. J., Data-Source Marking in the Jaqui Languages, v: The Linguistic Coding of Epistemology (ur. Chafe, W., Nichols, J.), Norwood 1986, str. 113-136.

Izquierdo Alegría in dr., Un acercamiento a los fundamentos de la evidencialidad y a su recepción y tratamiento en la lingüística hispánica, v: La evidencialidad en español (ur. González Ruiz, R. in dr., Madrid 2016, str. 9-45.

Kany, C. E., Impersonal dizque and its variants in American Spanish, Hispanic Review 12, 1944, str. 168-177.

Kany, C. E., Sintaxis hispanoamericana, Madrid 1969.

Lyons, J., Semantics 1, Cambridge 1977.

Magaña, E., El paso de 'dice que' a 'dizque', de la referencia a la evidencialidad, Constribuciones desde Coatepec 8, 2005, str. 59-70.

Olbertz, H., Dizque en el español andino ecuatoriano: conservador e innovador, Encuentros y conflictos. Bilingüismo y contacto de lenguas en el mundo andino (ur. Olbertz, H., Muysken, P.). Madrid 2005, str. 77-94.

Olbertz, H., Dizque in Mexican Spanish: the subjectification of reportative meaning, Rivista di Linguistica 19/1, 2007, str. 151-172.

Palmer, J. F., Mood and Modality, Cambridge 2001 [1987].

Pisanski Peterlin, A., So prevedena poljudnoznanstvena besedila v slovenščini drugačna od izvirnih? Korpusna študija na primeru epistemske naklonskosti, Slavistična revija 63/1, 2015, str. 29-43.

Smolej, M., Členek v sodobnem slovenskem jezikoslovju, Obdobja 34: Slovnica in slovar - aktualni jezikovni opis. (ur. Smolej, M.), Ljubljana 2015, str. 671-178.

Smolej, M., Členki kot besedilni povezovalci, Jezik in slovstvo 49/5, 2004b, str. 45-57.

Smolej, M., Obvezni in neobvezni členki, Slavistična revija 52/2, 2004a, str. 144-155.

Travis, C., Dizque: a Colombian evidentiality strategy, Linguistics 44, 2006, str. 12691297.

Verdonik, D., Jezikovni elementi spontanosti v pogovoru: Diskurzni označevalci in popravljanja, Maribor 2007.

Willet, T., A Cross-Linguistic Survey of the Grammaticalization of Evidentiality, Studies in Language 12, str. 51-97.

Wright, G. H. von, A Treatise on Induction and Probability, London 1951.

Žele, A., Reševanje nekaterih skladenjskih vprašanj v slovenščini glede na razpoložljive teorije in metode, Slavistična revija 56 (ur. Derganc, A.), 2008, str. 161-76. 


\section{Barbara Pihler Ciglič}

\section{Evidencialna branja prislova dizque $v$ nekaterih različicah ameriške španščine in njegove ustreznice $v$ slovenščini}

Ključne besede: dizque, evidencialnost, epistemska naklonskost, ameriška španščina, slovenski naklonski členki

Prispevek obravnava izražanje evidencialnosti, torej kazanja na vir informacij $\mathrm{v}$ izjavi, s pomočjo slovnične kategorije dizque v ameriških različicah španščine ter primerja njegove evidencialne vrednosti s slovenskimi ustreznicami v izbranih literarnih besedilih. V študiji je najprej predstavljena konceptualna prepletenost pojmov epistemske naklonskosti in evidencialnosti ter zavzame pozicijo, ki v njiju vidi dve ločeni kategoriji. Sledi predstavitev osrednjih smernic najnovejših raziskav o prislovu dizque, ki postaja $\mathrm{v}$ ameriških različicah španščine vse pogosteje rabljena oblika. Tako po oblikoslovno-skladenjskih kot semantično-pragmatskih značilnostih se zdi, da sta naklonska členka menda in baje njegovi najbližji slovenski ustreznici, zato avtorica v nadaljevanju pretrese nekatere besednovrstne podobnosti in skladenjska ujemanja ter opredeli kategorijo t. i. evidencialnih označevalcev. Sledi analiza prevodnih ustreznic dizque v izbranih leposlovnih besedilih. Analiza primerov pokaže, da so pri signaliziranju evidencialnih pomenov najprimernejše slovenske ustreznice dizque prav naklonski členki, čeprav je enako pogosta tudi struktura z glagolom rekanja. 


\section{Evidential readings of adverb dizque in some varieties of American Spanish and its equivalents in Slovene}

Keywords: dizque, evidentiality, epistemic modality, American Spanish, Slovenian modal particles

The present article studies the expression of evidentiality, essentially the indication of the source of information in the statement, through the grammatic category dizque in some varieties of American Spanish, and compares its evidential values with Slovene equivalents in selected literary texts. The study begins by introducing the conceptual interweaving of epistemic modality and evidentiality, and presents a position that sees them as two separate categories. This is followed by a critical overview of the main guidelines for the latest research on dizque, which is becoming increasingly used in varieties of American Spanish. In terms of morphological, syntactic and semantic-pragmatic characteristics, it seems that the nearest Slovene equivalents of dizque should be Slovene modal particles menda and baje, and therefore the next chapter examines certain morphological similarities and syntactic matches, as well as defines the category of so-called evidential markers. Following this is the analysis of the translation equivalents of dizque in selected literary texts. The results of the comparative study indicate that the most appropriate Slovene equivalents of dizque, when it signalizes the evidential meanings, are precisely the modal particles, although the structure with the verb of speech is equally frequent. 